\title{
The effect of BMI on the mid-term clinical outcomes of mobile-bearing unicompartmental knee arthroplasty
}

\author{
Yikai Liu ${ }^{1}$, Huanshen Gao ${ }^{2}$, Tao Li ${ }^{1}$, Zian Zhang ${ }^{1}$ and Haining Zhang ${ }^{1 *}$
}

\begin{abstract}
Objective: To evaluate the impact of body mass index (BMI) on the mid-term clinical outcomes and survival in patients receiving a mobile-bearing unicompartmental knee arthroplasty (UKA).

Methods: We retrospectively collected data from 355 patients who underwent UKA from June 2006 to June 2015, with a mean follow-up of $106.5 \pm 22.5$ months. Patients were assigned into four groups based on their BMI before surgery: normal weight group (BMI $\left.18.5 \sim 22.9 \mathrm{~kg} / \mathrm{m}^{2}\right)$, overweight group $\left(23 \sim 24.9 \mathrm{~kg} / \mathrm{m}^{2}\right)$, obesity group $(25 \sim 29.9 \mathrm{~kg} /$ $\mathrm{m}^{2}$ ), and severe obesity group $\left(\geq 30 \mathrm{~kg} / \mathrm{m}^{2}\right.$ ). The knee society score (KSS), knee society function score (KSFS), hospital for special surgery score (HSS), and range of motion (ROM) were assessed before the operation and at the last followup. The femorotibial angle (FTA) was assessed after the operation immediately and at the last follow-up. Kaplan-Meier survival analysis was performed among the four groups.
\end{abstract}

Results: The KSS, KSFS, and HSS in all groups were markedly improved compared with the preoperative values $(p<0.001)$, but the ROM score was not significantly different ( $p>0.05)$. There were significant differences in KSS $(p<0.001)$ and HSS ( $p=0.004)$ across the four BMI groups, and these differences were due to the severe obesity group. All groups exhibited an inclination of knee varus deformity at the last follow-up $(p<0.05)$. Moreover, no marked difference in the implant survival rate was found among the different groups $(p=0.248)$, or in the survival curves $(p=0.593)$.

Conclusions: BMI does not influence the implant survival rate. The postoperative functional and quality-of-life scores were significantly improved in all groups. Obese $\left(\mathrm{BMI} \geq 30 \mathrm{~kg} / \mathrm{m}^{2}\right)$ individuals should not be excluded from UKA.

Keywords: Arthroplasty, replacement, knee, Body mass index, Obesity

\section{Introduction}

Obesity plays a significant role in the occurrence and progression of knee osteoarthritis (OA) [1-3], and globally, obesity has been predicted to enhance the demand for knee replacement surgery [4-6]. Nevertheless, morbid obesity is traditionally considered a contraindication to knee replacement surgery due to low long-term

*Correspondence: zhanghaining1976@126.com

${ }^{1}$ Department of Joint Surgery, the Affiliated Hospital of Qingdao University, Qingdao 266000, Shandong Province, China

Full list of author information is available at the end of the article implant survival. Unicompartmental knee arthroplasty (UKA) is a common therapeutic regimen for end-stage medial compartment OA. Even with many advantages over total knee arthroplasty (TKA), the revision rate of UKA is higher [7, 8]. Morbid obesity increases intraoperative complications including inadequate exposure and implant alignment, as well as postoperative complications such as tibial loosening, wound complications and respiratory complications [6-12]. Different survival results of fixed-bearing UKA have been reported, while the effects of high BMI on mobile-bearing UKA clinical outcomes are still unclear. In fact, several factors, such original author(s) and the source, provide a link to the Creative Commons licence, and indicate if changes were made. The images or other third party material in this article are included in the article's Creative Commons licence, unless indicated otherwise in a credit line to the material. If material is not included in the article's Creative Commons licence and your intended use is not permitted by statutory regulation or exceeds the permitted use, you will need to obtain permission directly from the copyright holder. To view a copy of this licence, visit http://creativecommons.org/licenses/by/4.0/. The Creative Commons Public Domain Dedication waiver (http://creativeco mmons.org/publicdomain/zero/1.0/) applies to the data made available in this article, unless otherwise stated in a credit line to the data. 
as small sample size, fewer revision cases, short-term follow-up, or simple binary analysis, have greatly limited the previous investigations studying the effect of BMI on the prognosis of UKA. Compared to fixed-bearing UKA, mobile-bearing UKA has less bearing abrasion but a higher bearing dislocation rate. Mobile-bearing prevents higher maximum peak pressures to concentrate on a small area and reduces bearing abrasion [13], but whether this change will benefit obese patients is unclear due to the possibility of increasing bearing dislocationinduced prosthesis revision [13]. We propose the hypothesis that a high BMI does not increase the revision rate, and is not a contraindication to mobile-bearing UKA. Here, we focused on the impact of BMI on mid-term clinical outcomes of UKA and performed a retrospective comparative study composed of 355 patients undergoing medial UKA.

\section{Materials and methods}

A retrospective case note review consisting of several variables was performed for each individual, such as age at surgery, sex, weight, height, follow-up duration, and postoperative complications. The BMI of patients was determined using the following formula: weight/height [2]. According to the BMI classification standards of Asian adults defined by the World Health Organization (WHO) [14], the patients were assigned into four categories: normal body mass group (BMI $18.5-22.9 \mathrm{~kg} / \mathrm{m}^{2}, 33$ cases with $38 \mathrm{knees}$ ), overweight group (BMI $23-24.9 \mathrm{~kg} / \mathrm{m}^{2}, 35$ cases with $43 \mathrm{knees)}$ ), obesity group (BMI $25-29.9 \mathrm{~kg} / \mathrm{m}^{2}, 97$ cases with 110 knees), and severe obesity group (BMI $\geq 30 \mathrm{~kg} / \mathrm{m}^{2}, 28$ cases with 38 knees). This study was approved by the ethics committee, and all patients signed informed consent forms.

\section{Surgical procedures}

Oxford mobile-bearing UKA (Biomet, Inc.,Warsaw, IN) was used in operation. General anaesthesia combined with midthigh saphenous nerve block was applied to the patient. A tourniquet was used at the beginning of the operation. A paramedial incision is made from the superomedial edge of the patella to the medial border of the tibial tubercle. Bone resection was performed according to the order of cutting the tibial plateau, then the posterior condyle of the femur, milling the distal femur, and anti-impingement milling. The amount of osteotomy was measured before bone cutting. Minor adjustment of bone resection was made if the extension or flexion gap was not appropriate. The goal tibial slope is $7^{\circ}$, and this slope is built into the tibial guide. Finally, bone cement was applied, and the prosthesis was placed. The detailed procedures were performed according to Oxford experience [15].

\section{Outcomes}

Preoperative and postoperative functional scores and imaging data were collected and recorded by an independent professional. Clinical outcomes were assessed using the knee society score (KSS), knee society function score (KSFS), hospital for special surgery score (HSS), and range of motion (ROM). In the radiological evaluation, the femorotibial angle (FTA) was evaluated based on the Oxford radiological criteria. Preoperative and postoperative FTA were determined according to the angle between the two lines drawn from the centres of the femur and tibia (over $175^{\circ}$ was varus, $170^{\circ}-175^{\circ}$ was normal, and below $170^{\circ}$ was valgus). A revision was defined as the removal, exchange, or addition of an implant component, including bearing exchange for bearing dislocation, or conversion to TKA.

\section{Statistical analysis}

The statistical analysis was performed using SPSS 23.0 software for Windows, and the survival curve was made by GraphPad Prism 8.0. Statistical analyses were two-sided, and significance was set at $P<0.05$. Preoperative and postoperative KSS, KSFS, HSS, FTA, and ROM were calculated, and ANOVA was used to compare these variables across various BMI groups. Paired t-tests were adopted to determine differences within BMI groups. The revision was evaluated using KaplanMeier survival analysis.

\section{Missing values}

A total of 31 patients with 35 knees were lost to followup. Therefore, their revision status remained unknown.

\section{Results}

\section{Cohort demographics}

A total of 355 patients (408 knees) with medial compartment $\mathrm{OA}$ of the knee, who were treated with mobile-bearing UKA from June 2005 to June 2015, were selected as the research subjects in the present study. The postoperative mean follow-up was $106.5 \pm 22.5$ months (range $80 \sim 136$ months). Of these patients, 31 patients ( 35 knees) were lost to the followup, and thus, 324 patients (373 knees) who met the inclusion criteria were ultimately enrolled in the present work. There were no marked differences in age $(\mathrm{F}=1.392, p=0.245)$, sex $\left(\mathrm{X}^{2}=3.347, p=0.341\right)$, or follow-up time $(\mathrm{F}=0.517, p=0.671)$ among the four BMI groups, which indicated a similar patient characteristic of different BMI groups at baseline. (Table 1). 
Table 1 Cohort demographics

\begin{tabular}{lllll}
\hline BMI group & $\begin{array}{l}\text { N patients } \\
\text { (knees) }\end{array}$ & Mean age & Sex (M: F) & Mean follow-up \\
\hline$<23$ & $54(64)$ & $67.4 \pm 9.0$ & $17: 37$ & $119.6 \pm 16.7$ \\
$23-<25$ & $69(81)$ & $65.1 \pm 8.2$ & $25: 44$ & $114.3 \pm 21.8$ \\
$25-<30$ & $153(172)$ & $65.6 \pm 7.2$ & $50: 103$ & $115.8 \pm 26.5$ \\
$\geq 30$ & $48(56)$ & $64.2 \pm 10.2$ & $10: 38$ & $116.2 \pm 25.0$ \\
Test value & & $\mathrm{F}=1.392$ & $X^{2}=3.347$ & $\mathrm{~F}=0.517$ \\
$P$ value & & 0.245 & 0.341 & 0.671 \\
\hline
\end{tabular}

\section{KSS and KSFS}

The postoperative KSS and KSFS were dramatically improved in all groups compared with their corresponding preoperative values (Table 2; Table 3; $p<0.001$ ), which indicated that UKA improved function to a large extent regardless of weight. Moreover, significantly different KSS at the last follow-up was found among the four groups (Table 2; $F=10.344$, $p<0.001)$. Multiple comparisons were performed, revealing that the KSS in the severe obesity group was significantly lower than other three groups (Table 2; $p<0.05)$, while the KSS did not significantly differ across the normal body mass group, overweight group and obesity group (Table 2; $p>0.05$ ), which implied that the KSS improvement has negative correlation with BMI.
HSS

The preoperative HSS was significantly improved in all groups compared with their postoperative values (Table $4 ; p<0.001)$. Moreover, the largest absolute increase in reported HSS (Table 4; mean HSS improvement $30.66 \pm 9.84$ ) was found in the normal body mass group. In addition, significantly different HSS scores at the last follow-up were found among the four groups. (Table 4; $\mathrm{F}=4.564, p=0.004$ ). Multiple comparisons were performed at the last follow-up, revealing that the HSS in the severe obesity group was significantly lower than other three groups (Table $4 ; p<0.05$ ), while the HSS did not significantly differ across the normal body mass group, overweight group and obesity group (Table 4; $p>0.05)$.

\section{ROM}

There was no significant improvement in ROM for each group (Table $5 ; p>0.05$ ). No significant difference in ROM was found among the four groups preoperatively or at the last follow-up (Table 5; $p>0.05$ ), which indicated that BMI has no effect on the long-term ROM.

FTA

$\mathrm{X}$-rays of the knee joint in the front and side positions and X-rays of the whole lower limb in the weightbearing condition were performed for each inpatient to ensure the accurate measurement of FTA. The mean and

Table 2 Comparison of the KSS among the four groups before the operation and at the last follow-up ( $\bar{x} \pm s)$

\begin{tabular}{|c|c|c|c|c|c|}
\hline BMI group & Preoperation & Last follow-up & $\begin{array}{l}\text { Difference between last } \\
\text { follow-up and preop }\end{array}$ & $T$ value & $P$ value \\
\hline$<23$ & $46.24 \pm 12.65$ & $89.15 \pm 7.26$ & $42.91 \pm 10.27$ & 30.70 & $<0.001$ \\
\hline $23-<25$ & $47.31 \pm 14.17$ & $87.21 \pm 13.26$ & $39.9 \pm 15.14$ & 21.89 & $<0.001$ \\
\hline $25-<30$ & $49.23 \pm 13.93$ & $90.37 \pm 9.31$ & $41.14 \pm 13.70$ & 37.14 & $<0.001$ \\
\hline$\geq 30$ & $45.98 \pm 11.88$ & $80.05 \pm 16.51$ & $34.07 \pm 16.36$ & 14.43 & $<0.001$ \\
\hline F value (between groups) & 1.120 & 10.344 & & & \\
\hline$P$ value (between groups) & 0.341 & $<0.001$ & & & \\
\hline
\end{tabular}

Table 3 Comparison of the KSFS among the four groups before the operation and at the last follow-up $(\bar{x} \pm s)$

\begin{tabular}{|c|c|c|c|c|c|}
\hline BMI group & Preoperation & Last follow-up & $\begin{array}{l}\text { Difference between last follow-up } \\
\text { and preoperation }\end{array}$ & $T$ value & $P$ value \\
\hline$<23$ & $55.44 \pm 13.06$ & $89.83 \pm 12.76$ & $34.39 \pm 15.59$ & 16.21 & $<0.001$ \\
\hline $23-<25$ & $53.16 \pm 10.48$ & $87.47 \pm 14.74$ & $44.31 \pm 20.77$ & 17.72 & $<0.001$ \\
\hline $25-<30$ & $54.39 \pm 20.27$ & $85.01 \pm 19.51$ & $30.62 \pm 21.28$ & 17.80 & $<0.001$ \\
\hline$\geq 30$ & $52.63 \pm 16.11$ & $82.28 \pm 20.67$ & $29.65 \pm 19.61$ & 10.48 & $<0.001$ \\
\hline F value (between groups) & 0.317 & 1.824 & & & \\
\hline$P$ value (between groups) & 0.813 & 0.143 & & & \\
\hline
\end{tabular}


Table 4 Comparison of the HSS among the four groups before the operation and at the last follow-up ( $\bar{x} \pm s)$

\begin{tabular}{|c|c|c|c|c|c|}
\hline BMI group & Preop & Last follow-up & $\begin{array}{l}\text { Difference between last } \\
\text { follow-up and preop }\end{array}$ & $T$ value & $P$ value \\
\hline$<23$ & $60.61 \pm 11.60$ & $91.27 \pm 10.37$ & $30.66 \pm 9.84$ & 22.90 & $<0.001$ \\
\hline $23-<25$ & $62.49 \pm 10.21$ & $90.02 \pm 11.16$ & $27.53 \pm 10.30$ & 22.20 & $<0.001$ \\
\hline $25-<30$ & $61.36 \pm 8.03$ & $87.96 \pm 10.87$ & $26.60 \pm 8.43$ & 39.03 & $<0.001$ \\
\hline$\geq 30$ & $59.63 \pm 14.67$ & $83.41 \pm 14.90$ & $23.78 \pm 14.53$ & 11.34 & $<0.001$ \\
\hline Fvalue (between groups) & 0.787 & 4.564 & & & \\
\hline$P$ value (between groups) & 0.502 & 0.004 & & & \\
\hline
\end{tabular}

Table 5 Comparison of the ROM among the four groups before the operation and at the last follow-up $\left({ }^{\circ}, \bar{x} \pm s\right)$

\begin{tabular}{|c|c|c|c|c|c|}
\hline BMI group & Preop & Last follow-up & $\begin{array}{l}\text { Difference between last } \\
\text { follow-up and preop }\end{array}$ & $T$ value & $P$ value \\
\hline$<23$ & $123.3 \pm 8.7$ & $123.6 \pm 7.5$ & $0.3 \pm 3.9$ & 0.54 & 0.59 \\
\hline $23-<25$ & $120.1 \pm 9.7$ & $121.0 \pm 12.6$ & $0.9 \pm 7.3$ & 0.95 & 0.35 \\
\hline $25-<30$ & $121.9 \pm 8.4$ & $122.5 \pm 10.1$ & $0.6 \pm 4.0$ & 1.86 & 0.07 \\
\hline$\geq 30$ & $119.3 \pm 12.1$ & $119.7 \pm 11.4$ & $0.4 \pm 5.3$ & 0.52 & 0.60 \\
\hline Fvalue (between groups) & 2.107 & 1.542 & & & \\
\hline$P$ value (between groups) & 0.099 & 0.204 & & & \\
\hline
\end{tabular}

standard deviation of immediately postoperative FTA was $173.5^{\circ} \pm 2.4^{\circ}$, while it was $174.9^{\circ} \pm 2.7^{\circ}$ at the last follow-up. All groups were in the range of $170^{\circ}-175^{\circ}$, except the severe obesity group at the last follow-up. Significantly different FTA was found among the four groups at the last follow-up rather than immediately postoperation (Table 6; $p<0.05$ ). Multiple comparisons showed that the FTA in the severely obese group was significantly higher than that in the other three groups (Table $6 ; p<0.05$ ), which implied a slight varus tendency in the severely obese patients.

\section{Postoperative complications and prognosis}

All patients in this study had no severe complications, such as venous thrombosis of the lower limbs, or cardiovascular and cerebrovascular accidents, and no cases of revision were caused by periprosthetic joint infection. Moreover, nine patients had unexplained abnormal joint noise and joint noise, while the symptoms gradually disappeared over time. There were seventeen revisions, including twelve cases due to bearing dislocation, three cases due to the progression of lateral compartment OA, and two cases for aseptic loosening of tibial components. No revision occurred in patients with a BMI of $<23 \mathrm{~kg} / \mathrm{m}^{2}$. In addition, four cases of these revisions occurred in the group with a BMI of $18.5-22.9 \mathrm{~kg} / \mathrm{m}^{2}$, representing $4.9 \%$ of UKA in this group. Nine (5.2\% of the group) cases were found in the group with a BMI of $25-29.9 \mathrm{~kg} / \mathrm{m}^{2}$, and four $(7.1 \%)$ cases were found in the group with a BMI of $\geq 30 \mathrm{~kg} /$ $\mathrm{m}^{2}$. No correlation between indications for revision and BMI group was found.

Table 6 Comparison of the FTA among the four groups between the immediate postoperation and at the last follow-up $\left({ }^{\circ}, \bar{x} \pm s\right)$

\begin{tabular}{|c|c|c|c|c|c|}
\hline BMI group & $\begin{array}{l}\text { Last } \\
\text { follow-up }\end{array}$ & $\begin{array}{l}\text { Immediate } \\
\text { postoperation }\end{array}$ & $\begin{array}{l}\text { Difference between last follow-up } \\
\text { and immediate } \\
\text { postoperation }\end{array}$ & $T$ value & $P$ value \\
\hline$<23$ & $174.3 \pm 2.7$ & $173.4 \pm 2.4$ & $0.9 \pm 2.3$ & 2.88 & 0.006 \\
\hline $23-<25$ & $174.8 \pm 3.6$ & $173.6 \pm 2.7$ & $1.2 \pm 3.1$ & 3.22 & 0.002 \\
\hline $25-<30$ & $174.9 \pm 2.4$ & $173.3 \pm 1.9$ & $1.8 \pm 2.9$ & 7.25 & $<0.001$ \\
\hline$\geq 30$ & $176.0 \pm 2.9$ & $174.2 \pm 3.3$ & $1.8 \pm 2.7$ & 4.62 & $<0.001$ \\
\hline F value (between groups) & 3.219 & 1.740 & & & \\
\hline$P$ value (between groups) & 0.023 & 0.159 & & & \\
\hline
\end{tabular}


Table 7 Survival rate of the implant in four groups

\begin{tabular}{llll}
\hline BMI group & N knees & Number of revision & Survival rate \\
\hline$<23$ & 64 & 0 & $100 \%$ \\
$23-<25$ & 81 & 4 & $95.06 \%$ \\
$25-<30$ & 172 & 9 & $94.77 \%$ \\
$\geq 30$ & 56 & 4 & $92.86 \%$ \\
Entire cohort & 373 & 17 & $95.44 \%$ \\
At the last follow-up & $x^{2}=4.124$ & $\mathrm{P}=0.248$ & \\
$\begin{array}{l}\text { Survival curve com- } \\
\text { parison }\end{array}$ & & $\mathrm{P}=0.593$ & \\
\hline
\end{tabular}

The survival rate of UKA for patients with a BMI of $<23$ was $100 \%$, and it was $95.06,94.77$, and $92.86 \%$ for the groups with a BMI between 23 and $<25,25$ and $<30$ and $\geq 30$, respectively (Table 7; Fig. 1 ). Moreover, no significant difference in implant survival rate was found among the various groups $\left(\chi^{2}=4.124, p=0.248\right)$ at the last follow up. No difference in the prosthesis survival curve was found. $(p=0.593)$.

\section{Discussion}

The most important finding of our study was that both normal and high BMI patients showed acceptable clinical outcomes after UKA, even with significant differences of postoperative KSS and HSS compared with nonobese patients. Therefore, obesity should not be considered a contraindication of mobile-bearing UKA. For obese patients, mobile-bearing therapy is more strongly recommended than fixed-bearing therapy. Weight management is still beneficial for patients requiring UKA, as nonobese people have better functional scores in the long run.
Traditionally, obesity has been regarded as a contraindication in fixed-bearing UKA due to increased polyethylene wear and implant loosening [16]. Excessive weight or high BMI $\left(\mathrm{BMI} \geq 30 \mathrm{~kg} / \mathrm{m}^{2}\right)$ will increase the wear of the components, thereby shortening prosthesis survival [17]. Moreover, the negative effects of obesity on UKA include excessive incision tension, delayed healing, higher infection rates, and lower activity levels in later rehabilitation training.

In this study, we assessed the effects of BMI on the mid-term clinical outcomes after UKA. With an average follow-up of 106.5 months, the postoperative KSS and HSS in the severely obese group rather than the postoperative KSFS, were significantly decreased compared with those in the other three groups, which indicated worse postoperative functional scores in obese individuals accepting UKA. The functional scores of different studies vary due to different follow-up times and different BMI classifications. Plate et al. [18] reported that patients had an average OKS of 34 at 6 months after surgery, which was not affected by BMI. Woo et al. [19] have shown that obesity does not affect the 2-year clinical outcomes of UKA. These studies indicated that the negative effect of obesity on the clinical outcomes of UKA may be latent after a short time. In addition, our findings were also supported by a previous work [20] showing that there was a significant difference in postoperative clinical outcomes between patients in the severe obesity group and those with a BMI of $<30 \mathrm{~kg} /$ $\mathrm{m}^{2}$, and the clinical scores in the severe obesity group were lower. $\mathrm{Xu}$ et al. [21] conducted a 10-year followup survey and reported that the KSFS and Oxford knee score $(\mathrm{OKS})$ of patients with a BMI of $\geq 30 \mathrm{~kg} / \mathrm{m}^{2}$ were

\section{Survival curve}

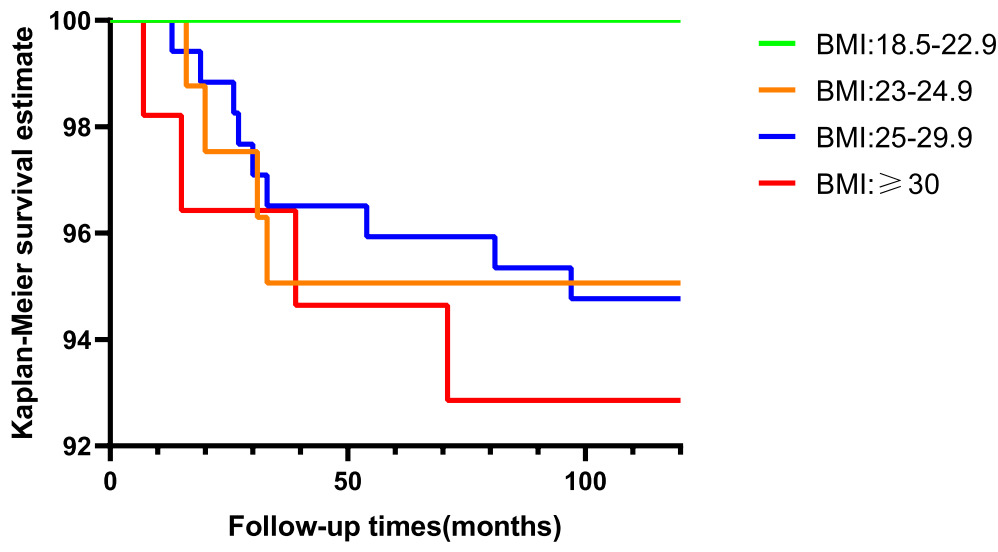

Fig. 1 The revision was evaluated using Kaplan-MeierKaplan-Meier survival analysis. No difference in the prosthesis survival curve was found among the four groups. Prosthesis survival curves of the four BMI groups. No significant difference of prosthesis survival was found between the four BMl groups: $18.5-22.9,23-24.9,25-29.9, \geq 30 .(p=0.593)$ 
significantly decreased at 10 years after surgery. However, a prospective study with a mean follow-up of 5.6 years conducted by Pandit et al. [22] showed that the clinical outcomes of 1000 mobile-bearing UKAs were similar between low weight patients and more than $82 \mathrm{~kg}$ patients. In a study with a minimum followup time of 7 years, Cavaignac et al. [23] found that there was no correlation between obesity and KSS. Plate et al. [18] suggested that BMI does not influence OKS, revision rates or readmission rates of robotic-assisted UKA in a mean follow-up of $34.6 \pm 7.8$ months. One reason that complicates the results is that multiple UKA prosthesis designs were used within single studies, for instance, fixed-bearing UKA and mobile-bearing UKA. Another reason is the differences in the BMI classification standards used by various studies for different races. The strength of our study is that only mobilebearing UKA is involved, which may reduce the confounding bias caused by different prosthesis designs. In addition, the BMI classification used in this study was the ASIA standard defined by the WHO, which is suitable for Asians.

We did not find any significant difference in the mean age of UKA between the severely obese group and the other three groups, which contradicts the previous findings that obese patients are more prone to develop OA at a young age [24]. Gandhi et al. [24] have shown that BMI is a significant independent predictor of age at TKA. The mean age of patients with a BMI of $\geq 35 \mathrm{~kg} / \mathrm{m}^{2}$ at the time of TKA was 8 years younger than that of individuals with a BMI of $<25 \mathrm{~kg} / \mathrm{m}^{2}$. Indeed, we see young patients suffer from OA in outpatient clinics, usually we take osteotomy rather than UKA or TKA when the pain cannot be alleviated by drugs. The use of this operation may contribute to the different findings of our study.

We evaluated whether there was varus or valgus tendency in different BMI groups after UKA by comparing the FTA immediately after the surgery and the value at the last follow-up. The FTA results showed a tendency of slight varus over time, especially in the severely obese group, while it was still within the normal range in the other three groups. Obesity leads to increased joint load, uneven forces within the joints, and more serious damage to the articular cartilage, ultimately increasing varus deformity of the lower limbs, which was confirmed in our current research.

No difference in the survival of implants among different BMI groups, and, in particular, no trend towards decreasing survival was found with an increase in BMI. The most common failure of mobile-bearing UKA is bearing dislocations. Anti-impingement milling in our operations included posterior osteophyte removal and anterior flange of the femoral component cleaning, which may largely reduce impingement-induced bearing dislocation. We emphasized the stability and integrity of the medial collateral ligament (MCL), and during bone resection and milling, we used a Tesla retractor to protect the MCL. In addition to test extension and flexion gap balancing, we performed an anterior drawer test after surgery to ensure a suitable bearing and less possibility of bearing dislocation. Our findings were supported by Murray et al. [25], showing that the survival rate of mobile-bearing UKA did not decrease with increasing BMI in 2438 patients with a mean follow-up of 5 years. Kuipers et al. [26] showed that there was no reduction in implant survival after a mean follow-up of 2.6 years. Naal et al. [27] and Xing et al. [28] reported that the survival rate was similar between nonobese and obese patients receiving fixed-bearing UKA after a mean follow-up of 2 and 4.5 years, respectively [16].

Compared to mobile-bearing UKA, fixed-bearing UKA seems less stable and reliable. Several studies have performed fixed-bearing UKA in patients with high BMI and shown varying survival rates . Tabor et al. [29] have shown that obese patients have greater survival rates after a follow-up of 20 years. In contrast, in a cohort consisting of 67 knees with a mean follow-up of 3 years, Bonutti et al. [30] reported that patients with a BMI of $>35 \mathrm{~kg} / \mathrm{m}^{2}$ have a higher risk of implant failure with a low survival rate of $88 \%$ compared with a survival rate of $100 \%$ in patients with a BMI of $<35 \mathrm{~kg} / \mathrm{m}^{2}$. During flexion and extension movement, pressure tends to concentrate on a small area, which may increase bearing abrasion and prosthesis revision rate in fixed-bearing UKA. Different surgeons, diffferent follow-up times and other confounding factors are responsible for the diverse findings. Therefore, it is necessary to perform large comparative studies to evaluate the impact of obesity on the different types of UKA.

This study also has some limitations. First, this study was a retrospective study, which might cause possible selection bias, as patients were selected from a single hospital. A multicentre study could reduce such biases and allow a large number of patients to be studied. Second, the number of patients receiving revision was relatively small, so the evaluation of different possible risk factors including obesity that contribute to revision is hard to perform. Future studies with a larger sample size would facilitate a better interpretation of survival.

\section{Conclusions}

In the present work, we showed that there was no difference in implant survival or indications for revision among patients with higher BMI. Moreover, we showed that the function and quality of life of all patients were remarkably improved after UKA. Although the severely 
obese (BMI $\geq 30 \mathrm{~kg} / \mathrm{m}^{2}$ ) group showed lower postoperative functional scores than the other three groups, the improvement compared to preoperative functional scores was significant. Therefore, obese individuals (BMI $\geq 30 \mathrm{~kg} / \mathrm{m}^{2}$ ) should not be excluded from UKA.

\section{Abbreviations}

OA: Osteoarthritis; UKA: Unicompartmental knee arthroplasty; TKA: Total knee arthroplasty; BMI: Body mass index; WHO: World Health Organization; KSS: Knee society score; KSFS: Knee society function score; HSS: Hospital for special surgery score; ROM: Range of motion; FTA: Femorotibial angle; ANOVA: Analysis of Variance; OKS: Oxford knee score.

\section{Acknowledgments}

Not applicable.

\section{Authors' contributions}

Yikai Liu: project conceptualization, data collection, result interpretation, final approval of the version to be submitted; Huanshen Gao: reporting \& editing, data validation; Tao Li: project conceptualization; Zian Zhang: result interpretation; Haining Zhang: result interpretation, final approval of the version to be submitted, and project guarantor. All authors reviewed the manuscript.

\section{Funding}

Not applicable.

\section{Availability of data and materials}

The datasets generated during and/or analysed during the current study are available from the corresponding author on reasonable request.

\section{Declarations}

\section{Ethics approval and consent to participate}

This study was approved by the medical ethics committee of the Affiliated Hospital of Qingdao University according to the Declaration of Helsinki, and informed consent was obtained from all individual participants included in the study. All methods were carried out in accordance with the Declaration of Helsinki.

\section{Consent for publication.}

Not applicable.

\section{Competing interests}

The authors declare that there is no competing of interest.

\section{Author details}

'Department of Joint Surgery, the Affiliated Hospital of Qingdao University, Qingdao 266000, Shandong Province, China. '2Department of Joint Surgery, Zaozhuang Municipal Hospital, Zaozhuang 277000, China.

Received: 24 September 2021 Accepted: 3 January 2022

Published online: 13 January 2022

\section{References}

1. Kulkarni K, Karssiens T, Kumar V, et al. Obesity and osteoarthritis. Maturitas. 2016;89:22-8. https://doi.org/10.1016/j.maturitas.2016.04.006.

2. Oliveira MC, Vullings J, van de Loo FAJ. Osteoporosis and osteoarthritis are two sides of the same coin paid for obesity. Nutrition. 2020;70:110486. https://doi.org/10.1016/j.nut.2019.04.001.

3. Wang T, He C. Pro-inflammatory cytokines: the link between obesity and osteoarthritis. Cytokine Growth Factor Rev. 2018;44:38-50. https://doi. org/10.1016/j.cytogfr.2018.10.002.

4. Culliford D, Maskell J, Judge A, et al. Future projections of total hip and knee arthroplasty in the UK: results from the UK clinical practice research
Datalink. Osteoarthr Cartil. 2015;23:594-600. https://doi.org/10.1016/j. joca.2014.12.022

5. Schwartz AM, Farley KX, Guild GN, et al. Projections and epidemiology of revision hip and knee Arthroplasty in the United States to 2030. J Arthroplast. 2020;35:S79-85. https://doi.org/10.1016/j.arth.2020.02.030.

6. Martin JR, Jennings JM, Dennis DA. Morbid obesity and Total knee Arthroplasty: a growing problem. J Am Acad Orthop Surg. 2017;25:188-94. https://doi.org/10.5435/JAAOS-D-15-00684.

7. Liddle $A D$, Judge $A$, Pandit $H$, et al. Adverse outcomes after total and unicompartmental knee replacement in 101,330 matched patients: a study of data from the National Joint Registry for England and Wales. Lancet. 2014;384:1437-45. https://doi.org/10.1016/S0140-6736(14)60419-0.

8. Hunt, L. P., Blom, A. W., Matharu, G. S. et al. Patients Receiving a Primary Unicompartmental Knee Replacement Have a Higher Risk of Revision but a Lower Risk of Mortality Than Predicted Had They Received a Total Knee Replacement: Data From the National Joint Registry for England, Wales, Northern Ireland, and the Isle of Man. J Arthroplasty 36, 471-477 e476, doi:https://doi.org/10.1016/j.arth.2020.08.063 (2021).

9. Mohammad, H. R., Matharu, G. S., Judge, A. et al. The Effect of Surgeon Caseload on the Relative Revision Rate of Cemented and Cementless Unicompartmental Knee Replacements: An Analysis from the National Joint Registry for England, Wales, Northern Ireland and the Isle of Man. J Bone Joint Surg Am 102, 644-653, doi:https://doi.org/10.2106/JBJS.19. 01060 (2020).

10. Liddle, A. D., Pandit, H., Judge, A. et al. Effect of Surgical Caseload on Revision Rate Following Total and Unicompartmental Knee Replacement. J Bone Joint Surg Am 98, 1-8, doi:https://doi.org/10.2106/JBJS.N.00487 (2016).

11. Kerkhoffs, G. M., Servien, E., Dunn, W. et al. The influence of obesity on the complication rate and outcome of total knee arthroplasty: a meta-analysis and systematic literature review. J Bone Joint Surg Am 94, 1839-1844, doi:https://doi.org/10.2106/JBJS.K.00820 (2012).

12. Smith $\mathrm{TO}$, Aboelmagd $\mathrm{T}$, Hing $\mathrm{CB}$, et al. Does bariatric surgery prior to total hip or knee arthroplasty reduce post-operative complications and improve clinical outcomes for obese patients? Syst Rev Meta-Analysis Bone Joint J. 2016;98-B:1160-6. https://doi.org/10.1302/0301-620X.98B9. 38024.

13. Ettinger $M$, Zoch JM, Becher $C$, et al. In vitro kinematics of fixed versus mobile bearing in unicondylar knee arthroplasty. Arch Orthop Trauma Surg. 2015;135:871-7. https://doi.org/10.1007/s00402-015-2214-x.

14. Consultation WHOE. Appropriate body-mass index for Asian populations and its implications for policy and intervention strategies. Lancet. 2004;363:157-63. https://doi.org/10.1016/S0140-6736(03)15268-3.

15. Hurst JM, Berend KR. Mobile-bearing unicondylar knee arthroplasty: the Oxford experience. Orthop Clin North Am. 2015;46:113-24. https://doi. org/10.1016/j.ocl.2014.09.007.

16. Deschamps G, Chol C. Fixed-bearing unicompartmental knee arthroplasty. Patients' selection and operative technique. Orthop Traumatol Surg Res. 2011;97:648-61. https://doi.org/10.1016/j.otsr.2011.08.003.

17. Foran JR, Mont MA, Rajadhyaksha AD, et al. Total knee arthroplasty in obese patients: a comparison with a matched control group. J Arthroplast. 2004;19:817-24. https://doi.org/10.1016/j.arth.2004.03.017.

18. Plate JF, Augart MA, Seyler TM, et al. Obesity has no effect on outcomes following unicompartmental knee arthroplasty. Knee Surg Sports Traumatol Arthrosc. 2017;25:645-51. https://doi.org/10.1007/ s00167-015-3597-5.

19. Woo, Y. L., Chen, Y. Q., Lai, M. C. et al. Does obesity influence early outcome of fixed-bearing unicompartmental knee arthroplasty? J Orthop Surg (Hong Kong) 25, 2309499016684297, doi:https://doi.org/10.1177/ 2309499016684297 (2017).

20. Amin AK, Clayton RA, Patton JT, et al. Total knee replacement in morbidly obese patients. Results of a prospective, matched study. J Bone Joint Surg Br. 2006;88:1321-6. https://doi.org/10.1302/0301-620X.88B10.17697.

21. Xu S, Lim WJ, Chen JY, et al. The influence of obesity on clinical outcomes of fixed-bearing unicompartmental knee arthroplasty: a ten-year followup study. Bone Joint J. 2019;101-B:213-20. https://doi.org/10.1302/0301620X.101B2.BJJ-2018-0969.R2

22. Pandit $H$, Jenkins $C$, Gill HS, et al. Unnecessary contraindications for mobile-bearing unicompartmental knee replacement. J Bone Joint Surg Br. 2011;93:622-8. https://doi.org/10.1302/0301-620X.93B5.26214. 
23. Cavaignac E, Lafontan V, Reina N, et al. Obesity has no adverse effect on the outcome of unicompartmental knee replacement at a minimum follow-up of seven years. Bone Joint J. 2013;95-B:1064-8. https://doi.org/ 10.1302/0301-620X.95B8.31370.

24. Gandhi R, Wasserstein D, Razak F, et al. BMl independently predicts younger age at hip and knee replacement. Obesity (Silver Spring). 2010;18:2362-6. https://doi.org/10.1038/oby.2010.72.

25. Murray DW, Pandit H, Weston-Simons JS, et al. Does body mass index affect the outcome of unicompartmental knee replacement? Knee. 2013;20:461-5. https://doi.org/10.1016/j.knee.2012.09.017.

26. Kuipers BM, Kollen BJ, Bots PC, et al. Factors associated with reduced early survival in the Oxford phase III medial unicompartment knee replacement. Knee. 2010;17:48-52. https://doi.org/10.1016/j.knee.2009.07.005.

27. Naal FD, Neuerburg C, Salzmann GM, et al. Association of body mass index and clinical outcome 2 years after unicompartmental knee arthroplasty. Arch Orthop Trauma Surg. 2009;129:463-8. https://doi.org/10. 1007/s00402-008-0633-7.

28. Xing Z, Katz J, Jiranek W. Unicompartmental knee arthroplasty: factors influencing the outcome. J Knee Surg. 2012;25:369-73. https://doi.org/ 10.1055/s-0031-1299666.

29. Tabor OB Jr, Tabor OB, Bernard M, et al. Unicompartmental knee arthroplasty: long-term success in middle-age and obese patients. J Surg Orthop Adv. 2005;14:59-63.

30. Bonutti PM, Goddard MS, Zywiel MG, et al. Outcomes of unicompartmental knee arthroplasty stratified by body mass index. J Arthroplast. 2011;26:1149-53. https://doi.org/10.1016/j.arth.2010.11.001.

\section{Publisher's Note}

Springer Nature remains neutral with regard to jurisdictional claims in published maps and institutional affiliations.

- fast, convenient online submission

- thorough peer review by experienced researchers in your field

- rapid publication on acceptance

- support for research data, including large and complex data types

- gold Open Access which fosters wider collaboration and increased citations

- maximum visibility for your research: over $100 \mathrm{M}$ website views per year

At BMC, research is always in progress.

Learn more biomedcentral.com/submissions 